\title{
Management of acid sulfate soils for sustainable rice cultivation in Malaysia
}

\begin{abstract}
Acid sulfate soils are an alternative aspect for the sustainable rice cultivation. Mostly these soils are not suitable for the crop production unless are effectively improved. Acid sulfate soils have toxicity due to the presence of high Aluminum ( $\mathrm{Al})$, and iron $(\mathrm{Fe})$ with low $\mathrm{pH}(<4.0)$. Usually these types of soils have nutrient deficiency especially in phosphorus, which causes poor plant growth and development. The soils need to be improved with some soil amendments like application of basalt, ground magnesium limestone and organic materials (biofertilizer) that can increase the soil $\mathrm{pH}$, improve soil nutrients and reduce the $\mathrm{Al}$ and Fe toxicity. The application of biofertilizer can enhance the rice plant growth, and yield by producing plant growth hormones (IAA) and organic acids that can chelate Al toxicity and solublize insoluble form of phosphorus in the soil.
\end{abstract}

Keyword: Aluminum; Basalt; Biofertilizer; Ground magnesium limestone; Iron toxicity 